\title{
La curiosidad de los alumnos en las clases de ciencias biológicas *
}

Susana Klimavicius*

\section{Resumen}

La búsqueda de las preguntas de los alumnos como reflejo de su curiosidad y las estrategias docentes que las promueven, fueron el corazón de la investigación. Sólo alumnos motivados, curiosos, creativos, con capacidad de hacerse preguntas y pensar estarán preparados para interpretar y comprender el mundo que los rodea.

Para el marco teórico se transitó por diferentes dimensiones y el diseño metodológico combinó instrumentos de la investigación cualitativa: observación de clases, entrevistas a tres profesores, dirección, bibliotecóloga y el relato de 157 alumnos que fueron una inagotable fuente de expresiones sobre cómo sienten la vida en el aula de Biología.

En el ecosistema liceal hemos percibido que muchos pueden ser los factores que inciden en la formulación de preguntas. El profesor desde su rol posee en sus manos la llave que abre la puerta de la curiosidad. La tarea no es sencilla, pero es posible; dependerá de las estrategias que se desplieguen.

\section{Abstract}

The search of the questions of the students like reflected of his curiosity and the teaching strategy those promoted it was the Herat of the investigation. Only the students motivated, curiosities, creative, with the capacity of make question's and think they will be prepared for interpret and understand the world they are surround.

For the theory marc they are travelled by different dimensions and the methodology design combining instruments of the qualitative investigation: observation of the classes, interview three professors, administration, librarian and the report of 157 students it was an inexhaustible spring of diverse expressions about they feel the life in the class-room of Biology.

In the high school ecosystem we have collected like many can be the factors like in the formulation of questions. The professor from his rol own in his hands the key like open the curiosity door. They work isn't easy but is possible; depend of the strategy like unfolding.

\section{Presentación del problema de investigación}

-¿Por qué es usted científico en lugar de médico, abogado u otro hombre de negocios, como lo son hoy otros hombres inmigrantes de su vecindario?

-Mi madre me hizo científico aunque nunca lo intentó.

cualquiera otra madre judía podría preguntar a su hijo después de la escuela:

"Y bien, ¿qué te han enseñado hoy?"

Pero no mi madre. Ella siempre me realizó una pregunta distinta. 
"Izzy", me decía, ¿hiciste una buena pregunta hoy?"

¡Esa diferencia -realizar buenas preguntas- me hizo un científico!

Isidor RABI

Premio Nobel de Física

Las expresiones de Isidor Rabi, la experiencia laboral en enseñaza Primaria y Secundaria, el avance de la ciencia a ritmos vertiginosos, la necesidad de una alfabetización científica desde la óptica del ciudadano, los cambios sociales con importantes problemas en el ámbito laboral y familiar, la democratización de la enseñanza, la didáctica centrada en los contenidos y el método, propuestas educativas que no satisfacen las necesidades de los educandos, los nuevos aportes que realiza la psicología y la lingüística a los docentes para llevar a cabo el proceso de enseñanza y de aprendizaje, son algunos de los motivos que llevan a formular el tema de investigación:

Explorar qué preguntan los alumnos, las posibles relaciones con las estrategias de enseñanza y el rol de la curiosidad en la formulación de las mismas.

\section{I ntroducción}

El niño es curioso por naturaleza, su interés por lo que lo rodea lo moviliza a investigar. Manipula, explora, experimenta, está permanentemente formulando preguntas. Se hace necesario entonces mantener encendida en el niño las luces de la curiosidad y el afán de saber, y de proporcionarle un ambiente que estimule esa curiosidad, a través de gran variedad de experiencias vitales.

Pero, ¿qué pasa con esas luces cuando se llega a la secundaria?

Cuando los niños pasan de la escuela a primer año del Ciclo Básico Único de Enseñanza Secundaria, observamos que se acercan con muchas expectativas, esperando que las "ciencias" sean interesantes, informativa, sorprendentes, hasta divertidas.

Pero a medida que pasan los meses los profesores ven, con gran pesar, que los alumnos se vuelven más pasivos, menos curiosos, están menos interesados y se limitan a realizar las tareas propuestas por los docentes con el fin de alcanzar mínimas calificaciones que le permitirán aprobar el curso, ya que no encuentran las mismas ni agradables ni estimulantes.

Frente a esta constatación surge una serie de interrogantes:

¿Qué ocurre en las aulas en el momento de enseñar y de aprender Biología?

¿Por qué los estudiantes se vuelven menos curiosos o están poco motivados por preguntar? ¿Qué tipos de preguntas realizan cuando las formulan?

¿Cómo fomenta el profesor de ciencias la interrogación por parte de los alumnos?

¿Cómo lo planifica y qué acciones realiza para lograrlo?

El punto de partida se centró en las propuestas de enseñanza como condicionantes de la curiosidad y por ende de la intervención de los alumnos. En el paradigma constructivista se encontraron aportes para el análisis y la reflexión. Sus diferentes investigadores proporcionaron bases teóricas que aluden a las formas de favorecer el desarrollo de mentes curiosas. Se recurrió a los estudios realizados sobre el contexto institucional, el aula, el currículum, las características de los profesores y de los alumnos, las distintas prácticas educativas; el lenguaje, el diálogo en el aula, la interrogación didáctica, la motivación, sin olvidar los estudios sobre la enseñanza y aprendizaje de las ciencias.

\section{2 - Universidad ORT Uruguay}




\section{Recorrida por el marco teórico}

Con el objetivo de su elaboración, se transitaron las siguientes dimensiones:

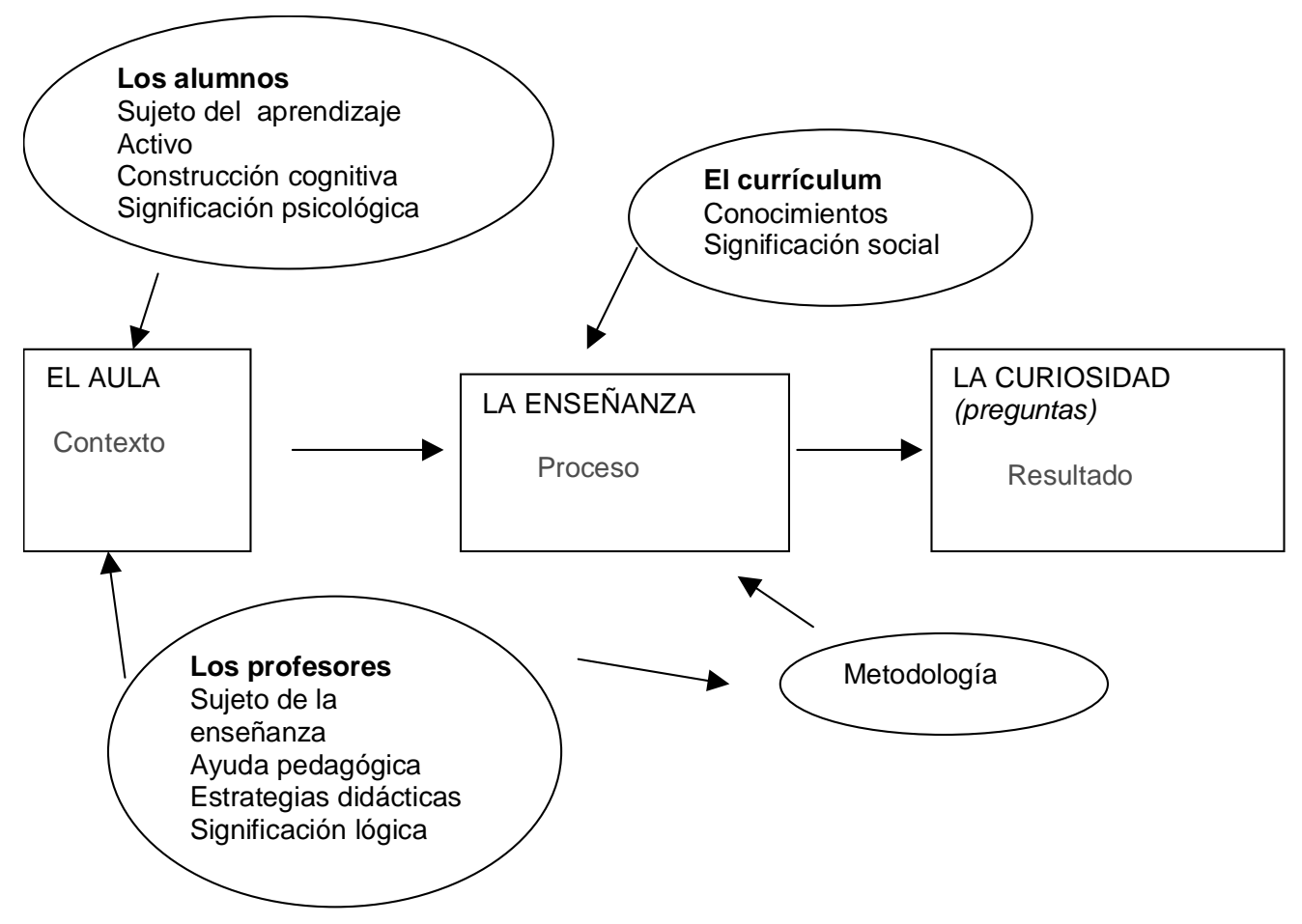

Cada dimensión presenta características propias, pero como en todo proceso dialéctico los mismos pierden su singularidad, se interrelacionan para configurar una estructura compleja que solo fue desglosada para su comprensión.

En las aulas encontramos diferentes conductas de estudiantes y profesores, que son el resultado de las diferentes personalidades de los protagonistas, en combinación con sus historias, en torno a un contenido disciplinar por aprender.

En el momento actual de la cultura que llamamos postmodernidad (época del desencanto, del fin de las utopías, de la ausencia de los grandes proyectos), de enormes y vertiginosos cambios; se necesita mucha gente instruida y, lo que es más importante, capaz de "moverse hacia" el aprendizaje. Las metodologías tradicionales de enseñanza basadas en la transmisión de información no responden a estas necesidades actuales y no son capaces de generar motivaciones externas en los educandos.

Por eso, los profesores deberán en el momento de llevar adelante las clases, reflexionar sobre la responsabilidad que tienen frente a los alumnos, para no dedicarse a llenar a los estudiantes de datos, olvidándose que son seres humanos.

Luego de haber pasado por la lectura de diferentes autores de ayer, de hoy y de siempre se encontró aportes que permiten expresar que si los docentes: 
- adoptaran un estilo interactivo e incitativo;

- fueran capaces de romper las rutinas;

- crearan buenos climas de aula haciendo un buen uso del tiempo y el espacio;

- enseñaran un saber socialmente válido y significativo, desarrollando estrategias que favorecieran el debate en las clases a través del planteo de situaciones problemáticas, atendiendo las ideas previas de los estudiantes, utilizando recursos significativos e implementando actividades cooperativas;

- generaran discusiones a partir de preguntas abiertas, divergentes, incitantes;

- promovieran las interrogaciones de parte de los alumnos ayudando al conflicto cognitivo y sociocognitivo;

- apostaran a una metodología que logre el cambio conceptual

- desarrollaran en los alumnos hábitos, actitudes y valores, acorde con una postura democrática;

serían capaces de conformar personalidades autónomas sobre la base de mentes curiosas, que constituirían el sostén de ulteriores desarrollos personales.

Ahora más que nunca hay que intentar comprender la estructuración entre alumnoconocimiento-docente, con el fin de aprender a poner en su lugar las situaciones de aprendizaje; como dice Meiriu (1992): "he sido seducido, pero ello me ha permitido comprender esto o aprender aquello y lo que sé lo puedo identificar, reutilizarlo fuera del contexto de su aprendizaje; ahora soy yo el dueño y, aunque lleve aún durante un tiempo la huella de la(s) personas(s) mediante la(s) cual(es) he llegado a obtener estos conocimientos, soy capaz de confrontarlos con nuevas situaciones..."

Los docentes deberán desprenderse algunas veces de su rol y convertirse en seres más humanos, a comprender que son guías, que enseñan a APRENDER A CONOCER, A HACER, A VIVIR CON LOS DEMÁS y lo más difícil A SER; a ser tan curiosos como lo fueron de niños.

\section{En búsqueda del significado de curiosidad}

Sin lugar a dudas las interpretaciones sobre curiosidad, pueden ser tan variadas como los contextos en que se utiliza y las situaciones en que se encuentra y se hace referencia a ella. Se podría afirmar, como se ha escuchado en alguna ocasión, no es una "palabra muerta"; aludiendo a que no se puede "encasillarla", "estructurarla", "anquilosarla" como ocurre con tantas otras.

En consecuencia se optó como marco referencial para lo que expresa Wynne Harlen en "Enseñanza y aprendizaje de las ciencias" (1985) sobre curiosidad: “...una búsqueda del saber.”; en otro pasaje nos dice: "Un niño curioso quiere conocer, probar experiencias nuevas, explorar, descubrir aspectos relativos a su entorno." La autora hace referencia a la curiosidad como actitud: actitud necesaria para aprender.

Por lo expuesto se construyó un concepto de curiosidad: "actitud que desarrolla el alumno para saber, manifestándose a través de la formulación de preguntas que le permiten seguir transitando el camino a la comprensión". La misma iluminó, guió y orientó esta investigación sobre enseñanza. 


\section{Metodología}

El problema de la investigación sobre educación que se implementó, así como el de todas las de su estilo, reside en el carácter subjetivo y complejo de los fenómenos sociales cuyos resultados no pueden generalizarse ni transferirse a otras realidades.

No se pretendió comprobar hipótesis o teorías sino indagar, explorar la complejidad de la realidad del aula, en la cual todos los factores intervinientes son considerados, con libertad y la flexibilidad que requieran las situaciones, elaborando descripciones provisionales.

Sin lugar a dudas, muchas han de ser las maneras de llevar a cabo un trabajo de investigación; la calidad de novato no impidió conocer que la elección metodológica obedece a diferentes motivos como: el objeto de conocimiento a investigar; los propósitos que se persiguen; la posibilidad de acceso a las fuentes de información; la posición teórica, epistemológica y ética del investigador. Todo ello confluyó en la elección de una investigación cualitativa que combinó observaciones, entrevistas y relatos que permitieron una aproximación comprensiva al objeto de estudio.

Se desarrolló en el nivel de Enseñanza Secundaria correspondiente al Ciclo Básico cuyos grupos van de primero a tercer año. La unidad de análisis fueron los alumnos de primero (2 grupos con un total de 53 alumnos); segundo (3 grupos con un total de 68 alumnos) y tercer año (3 grupos con un total de 59 alumnos) de una institución privada de Montevideo.

El tipo de observación implementada respondió a las características de observación no participante. Durante las diferentes sesiones se identificaron elementos generales -contexto, clima áulico, temáticas abordadas- y aspectos grupales -socialización, actitudes y compromiso con el curso-. Se establecieron algunas pautas de observación que sirvieron de guía para la identificación de las características peculiares de cada escenario.

Se partió de ideas generales no sistematizando o estructurando lo observado sino por el contrario con libertad para ir registrando aquello que podría ayudar a comprender la incidencia de las estrategias docentes y el afloramiento de la curiosidad de los jóvenes.

Se realizaron entrevistas semidirigidas en profundidad a los tres docentes de los grupos involucrados, constituyendo la totalidad del profesorado de Biología. Se buscó explorar fundamentalmente aspectos vinculados a sus historias particulares: qué los llevó a inclinarse a la docencia, cómo ven a sus alumnos, si hacen o no preguntas, qué ocurre dentro de sus aulas, cómo creen que son sus clases y los aprendizajes priorizados. Todo ello relacionado con la curiosidad de los estudiantes del Ciclo Básico.

La Institución en la que se realizó la investigación cuenta con una Biblioteca y técnicos en el área durante todo el día. Los alumnos desde la primaria son estimulados a concurrir no solo con el objetivo de obtener textos y publicaciones para trabajar en su domicilio, sino para hacer uso del servicio en horas libres o después de clase y también consultar diferentes sitios web. Por lo expuesto se creyó conveniente realizar una entrevista a la bibliotecóloga para obtener otra mirada. Se diseñó un encuentro tratando de buscar nuevos datos o aquellos que confirmen los encontrados por otras vías. El acceso a la percepción de esta actora proporcionó, desde otro lugar y mirada, aportes significativos.

Para conocer y tratar de comprender el mundo de los adolescentes investigados, se realizaron ocho encuentros (uno con cada grupo) con el fin de solicitarles a los alumnos que expresaran por escrito sus vivencias en las clases de biología mediante un relato. 
Se obtuvo con ello 157 narraciones/relatos que constituyen la mayor riqueza de datos sobre apreciaciones de los principales involucrados en la investigación y son acopio importante de sus pensamientos, apreciaciones, puntos de vista, actitudes y sentimientos. Sus opiniones y manifestaciones se triangularon con las otras técnicas referidas en el proceso de análisis.

Los aspectos considerados para el estudio presentaron por consiguiente un fuerte componente subjetivo -perspectiva fenomenológica- en tanto refieren a las percepciones de los alumnos y de los docentes en lo que tiene que ver con:

a) Si son o no curiosos los alumnos

b) Los motivos que llevan a los alumnos a realizar preguntas en las clases de Ciencias Biológicas

c) Las estrategias docentes que estimulan la curiosidad de los alumnos.

\section{¿Qué se observó en las clases?}

En pleno siglo XXI, la tarea educativa centrada en la transmisión de los contenidos culturales de una generación a otra ya no puede sostenerse. Es necesario que se transforme en el vehículo más eficaz para lograr la transformación de los hombres, de sus ideas acerca del mundo y de sí mismos.

La disyuntiva radica entonces en:

- educar para informar y conservar aquellos saberes que la sociedad considera como verdades absolutas o;

- educar para transmitir y conservar la idea de que no existen sentidos únicos, ni cerrados, ni permanentes y reconocer que gracias a las equivocaciones, ideas a completar, transitoriedad y cuestionamientos de los saberes establecidos se puede acercar al conocimiento.

El alumno que se buscó es aquel para el que las reglas generales de la clase fallan para dar lugar a la pregunta que trata de alcanzar la comprensión del tema. Alumno vacío de algún saber, el alumno del desequilibrio, del movimiento, que deja atrás los conocimientos homogeneizantes y puede ver lo diferente, construyendo un nuevo orden.

Se observó a los alumnos curiosos como los alumnos en desequilibrio entre su experiencia previa y lo trabajado en clase, hablantes, abiertos, transgrediendo las "leyes" del aula, descentrándose permanentemente. Un alumno que se muestra como un sistema abierto con múltiples y variadas entradas y salidas, que al entrar en contacto con los otros puede hacer fallar cualquier predicción.

¿Cuál fue la o las estrategias docentes que permitieron el desequilibrio?

Simplemente (y no tan simplemente), aquella que le confiere su calidad de experto: tomar el emergente y cambiar por un momento el rumbo de la clase.

Docentes que tuvieron la capacidad (¿habilidad?) de permitir la participación de aquel alumno que intentaba la ruptura del diálogo triádico. Permitieron formular preguntas a partir de aprendizajes realizados anteriormente y la búsqueda de asociaciones que ayudaron a encontrar la respuesta. Cuando ello ocurrió la clase se convirtió en un "movimiento" de ideas con significado para los estudiantes. Se dio comienzo al desorden (certezas que caen); situaciones caóticas en principio e impredecibles desde la mirada del orden conocido, pero lo que están evidenciando es simplemente la necesidad de establecer nuevas comprensiones, nuevos órdenes.

Cabe señalar que otras de las estrategias de enseñanza observadas y que favorecieron el desarrollo de la curiosidad de los alumnos fueron en las que:

- Se indagaron los conocimientos de los alumnos invitándolos a que expliciten lo que saben 
y lo que no saben o es erróneo. Aquí se encuentra la denominada situación problema, lo que Ilama Meirieu $(1992,101)$ "un juego de presencia/ausencia, de conocimiento/ignorancia" que permitió surgir la curiosidad.

- $\quad$ En relación con lo expresado anteriormente, se establecieron situaciones para el debate, la discrepancia, estableciéndose el conflicto cognitivo.

- $\quad$ Se vincularon los temas trabajados con la importancia asignada por el alumno a aspectos de la vida diaria, se partió de sus intereses y se los involucró como seres humanos; ello permitió poner de manifiesto el interés de seguir investigando sobre el tema.

- Se diseñaron planificaciones flexibles que permitieron adecuar el tiempo programado a los tiempos de los alumnos para atender sus inquietudes.

- Se fomentaron interacciones con compañeros creando un clima de aula favorable, permitiendo que se sintieran escuchados y valorados; prevaleció la confianza, la comunicación abierta y se pudo asumir riesgos sin temor a las consecuencias. Se creó en los alumnos la sensación de que también son "dueños" de lo que están estudiando; de esta forma se compartió en cierta forma el "poder", especialmente cuando se los enfrentó a la realidad que ellos buscaban.

\section{¿Qué dijeron los alumnos?}

“...La biología puede o no, ser interesante, esto depende de distintos factores. Principalmente depende del maestro. El maestro debe hacer que el tema se discuta en la clase, que los alumnos interactúen unos con otros y con el maestro. De por sí hay temas dentro de la biología que son interesantes..."

“...No sé si he perdido el interés por un tema de la naturaleza de mis conocimientos y/o personal o quizás hayan determinadas actuaciones por parte del profesor, sinceramente, como dije biología no es una materia que me interese demasiado,..."

Clara y sencillamente expresan lo que sienten, con un hondo y profundo conocimiento sobre lo que significa aprender y enseñar. ¿No están implícitamente expresando "no nos subestimen"? ¿No demandan de los docentes un cambio del camino trazado en las clases? ¿Reclaman modelos docentes que permitan un co-pensar, un dialogar?

El sistema de relaciones sociales: docente-alumno, docente-alumno-institución educativa instala el dilema ¿hasta dónde están dispuestos los docentes, las instituciones, a sostener, promover e incluso tolerar la emergencia de lo nuevo? ¿Cuáles son los condicionamientos histórico-sociales, ideológicos y pedagógicos? Cuando está afectado el placer de preguntar hay una restricción de la profundidad del pensamiento o de la esfera de intereses. Es observable que alumnos brillantes, inquietos, curiosos en un momento de su desarrollo se estancan, se desinteresan.

En el período en que se despierta la actividad intelectual, la aceptación libre de ideas puede verse rechazada por diferentes motivos, si hay "represión" sobre la curiosidad infantil o del adolescente, se "reprimen" las indagaciones más profundas. Al retener el placer de preguntar se puede instalar un rechazo inconsciente a la investigación y la curiosidad, que "otro" (institución, docente), desde lo implícito ha calificado como "trasgresión" porque puede desestabilizarlo. Se instala un miedo a la indagación del destino social, institucional y vincular de las necesidades de los sujetos en la estructura liceal.

Miedo a tener que reconocer que existen cosas ignoradas conduce al sujeto a evitar dudas, a huir de la profundidad, se piensa según la expectativa del "otro". 
De lo que antecede surgen nuevas interrogantes:

¿Qué necesidades son reconocidas en el liceo?

¿Qué metas y qué caminos se le ofrecen a esas necesidades en el orden social, Institucional, en el aula?

¿Cuáles son desconocidas o negadas y cuáles son descalificadas o sancionadas?

\section{¿Qué desean los alumnos?}

Una pregunta, una interrogante bien formulada por un ser humano puede provocar una "revolución" y la revolución de las ideas podría cambiar al mundo. En lugar de llenar las cabezas con respuestas que después se evalúan, el reto sería enseñar a los alumnos a que se hagan grandes preguntas. ¿Esto no será lo que requirieren los alumnos investigados?

"A mí me gustaría que en ciencias nos hagan preguntas que nos dejen pensando y que otras veces de estas preguntas surjan más preguntas, es decir que no nos hagan las típicas preguntas que tienen una única respuesta, sino que nos hagan pensar y reflexionar."

Piden que se les den oportunidades para tomar iniciativa en situaciones de aprendizaje; tomar decisiones por sí mismos, que no siempre se les diga qué deben hacer. Son capaces de usar su propio juicio crítico para decidir qué pasos estratégicos dar, cómo y cuándo darlos.

La mayoría de los adolescentes investigados no coincide con la imagen del adolescente poco reflexivo, acrítico, fruto de la cultura de la postmodernidad.

"...A mi me gusta preguntar, intento preguntar en biología pero no me dan la palabra.....Me gustaría que nos den una vez cada dos semanas una clase para expresar nuestras dudas..."

"...Personalmente, me gusta mucho debatir, expresar mi opinión, siempre con respeto al profesor, ..."

Dudar, opinar, investigar, entender, estudiar, resolver, saber, pensar, son algunas de las palabras dichas por los propios alumnos y que deberían estar presentes en el aula; son palabras que forman parte del vocabulario del lenguaje de pensamiento, ¿reclaman un "aula para pensar"?

Si se articula la curiosidad con el pensamiento crítico y creativo solicitado por los alumnos, el cual es necesario para el desarrollo del espíritu científico, nos encontramos con alumnos curiosos, solamente que la curiosidad se encuentra oculta.

\section{¿Qué otros aportes hacen los alumnos?}

Los alumnos consideran que demostrarían curiosidad cuando:

- se sienten considerados, reconocidos, valorados y estimulados a que sigan expresando sus ideas, de esa manera sienten confianza; sienten que pueden.

- la temática trabajada se encuentra relacionada con hechos, fenómenos, que estén vinculado directa o indirectamente con su cuerpo.

- los docentes estimulan el debate, escuchan más de lo que hablan, encuentran la estrategia para manejar la falta de tiempo en el aula para que los alumnos se expresen. Y, como una de las condicionantes que va contra la curiosidad es la calificación, el mayor desafío que deberían enfrentar los docentes es desarrollar un sistema de evaluación creativo que permita que los alumnos pregunten libremente.

\section{8 - Universidad ORT Uruguay}


- saben qué estrategias usar y cómo usarlas para comprender y aprender los contenidos disciplinares para no caer en el aburrimiento recurriendo a la memoria mecánica.

- los docentes trabajan los núcleos conceptuales del programa sin dejar al margen el desarrollo de habilidades experimentales como: observación, manipulación, formulación de preguntas, registro, entre otras.

- se les ofrece una variedad de recursos didácticos; los textos junto a las nuevas tecnologías, el laboratorio y las experiencias, las salidas de campo con el propósito de ponerlos en contacto con la "vida", investigando, realizando proyectos, de esta forma afloran las dudas, el interés y las preguntas que les harán comprender lo estudiado y compromisos individuales y grupales comenzando a dar sentido a sus experiencias.

Todos ellos son sin duda factores externos necesarios para que se manifieste la curiosidad, pero no los únicos. No se debe olvidar lo planteado por la teoría congnotivista, (Weiner y Covington) en la que se expresa que realizar una pregunta o no en clase depende en algunos casos de una motivación intrínseca, donde se pregunta para aprender (por la satisfacción personal de comprender), la conducta de estos alumnos -personas activas, curiosas, reflexivasestá determinada por su pensamiento y no por un motivo externo.

\section{Cara a cara con los docentes}

Los profesores, como cualquier otra persona, construyen sus creencias y percepciones a partir de su experiencia personal, de su educación y de sus valores. Sus creencias acerca de la educación son importantes puesto que de modo consciente e inconsciente, modelan la manera en que conciben el aprendizaje, la enseñanza y cómo se relacionan con los alumnos.

Pueden considerar el aprendizaje como un proceso natural o no y pueden ver la enseñanza como un proceso de facilitación y guía, o como un proceso de dirección y control del aprendizaje. Sus creencias sobre los alumnos, el aprendizaje y la enseñanza se dan en un contexto social e institucional; " "...los educadores pueden hacer muchas cosas, pero tienen que estar avalados en un contexto, en un sistema..." éstos afectan aquello que hacen, sus comportamientos y las prácticas en el aula.

Las opiniones giran en el sentido más amplio, desde las características del alumnado, las condiciones de la enseñanza, lo que ellos aspiran y lo que hacen y la realidad tal como la perciben.

\section{Relativo al alumnado y las estrategias docentes}

Se expresan sobre sus alumnos de distintas maneras, desde las claramente diferenciadas: maduros e inmaduros, responsables e irresponsables... y en otras ocasiones aparecen una percepción muy matizada que da lugar a diferentes imágenes, lo que resulta difícil de categorizar.

Encuentran a algunos infantiles, poco estudiosos, inquietos, etc., o bien estudiosos, responsables, y estos últimos especialmente en generaciones pasadas; características atribuidas a la edad, a factores sociales, familiares. Sus percepciones sobre los cambios generacionales, la visión de los cambios sociales desde el impacto de las nuevas tecnologías, la globalización etc., permite inferir que establecen una diferencia entre el momento actual y el pasado, todo ello repercutiendo en las aulas y las Instituciones Educativas. 
Con relación a como piensan y llevan a cabo sus estrategias de enseñanza: uso de diferentes recursos, el diálogo,... y cómo repercuten en el aula; consideran que poco "mueve" a los alumnos, escasa participación y compromiso frente a la tarea, siempre participan unos pocos, problemática en los tiempos, la presión del currículum, entre otras.

Pero no todo es negativo; lo que caracteriza a los profesores entrevistados es su capacidad de autocrítica desde el momento que aparecen dudas, inquietudes sobre lo que está pasando en sus clases, en ellos y sus alumnos; “... Y cómo pasa a veces que en determinado tema que vos decís al fin llegué.. ¿lo lograste tú? ¿lo lograron ellos? ¿lo logró el tema? O fue la conjunción de las tres cosas, me ha pasado eso. Y he intentado en otro grupo, en el mismo nivel, en la misma época y el enganche no se dio....” “...yo he venido dándole la vuelta, pero no encontraba, más allá..." lo que demuestra la capacidad de reflexionar.

Se recuerda las palabras de Ph. Jackson (2002) interpretando lo expresado por H. Adams sobre el problema de "las incertidumbres reales que entrañan las actividades de enseñar". Al interpretar las expresiones docentes desde esta óptica, las interrogantes que se plantean dan cuenta de la duda acerca del alcance de su influencia en el despertar la curiosidad de los alumnos: “... Hay cosas que están, que saltan, que se sabe que esto va a saltar, si no salta es porque vos no le llegaste...", "...cuando ellos tienen que responder saben responder..."

En ese reflexionar sobre lo que hacen, lo que deben y quieren hacer, de la significación de la temática a enseñar, las cuestiones psicológicas y el peso de la dimensión social actual, “...es que obedecen a una situación o es que están en la adolescencia...", se constata la manifestación de insatisfacción y preocupación por lo que ocurre en el aula, y lo más importante; la capacidad de plantear alternativas de cambio, posibles soluciones a los problemas: “... Yo me vi evolucionar, cambiar, perfeccionando algunas cosas, quitando otras. Porque,...¿cuánto daba yo antes, ¿cuánto corté ahora? Con esos cortes gané el poder dedicarme más a temas que a ellos les interesan. Poder responder a cosas, porque yo antes me veía... qué?, sí eso después....después lo contesto..."

Todo ese potencial manifestado a través de un espíritu crítico, los lleva a plantearse alternativas para el cambio, especialmente “...poder dedicarle más tiempo a ellos...” ya que reconocen que los alumnos son curiosos cuando la postura docente es flexible y logran un equilibrio entre el cuidado de la dimensión epistemológica y la psicológica en las prácticas de enseñanza “... Hacen preguntas; mira, los docentes tendríamos que ser mucho más abiertos..."

Quizás reconocen que la curiosidad no está reñida con el rigor intelectual y que un buen alumno debe ser curioso, debe ser capaz de formular preguntas e hipótesis explicativas a los problemas. Las nuevas generaciones a las que se enfrentan no escapan de la influencia de la época que les tocó vivir; la sociedad del conocimiento, conocimiento que crece a ritmos vertiginosos, la cultura de la imagen, de la inmediatez, la velocidad con que se conduce la información. A ello se le agrega la etapa de desarrollo en que se encuentran: primer período de la adolescencia, por lo que se puede tener la sensación de que los alumnos no son curiosos.

Pero la curiosidad aparece en sus expresiones cuando cuentan que se trabaja:

- con situaciones problemas abiertos o semiabiertos, situaciones que crean un conflicto que el alumno debe resolver y para el cual no dispone de un procedimiento rápido y directo que lo lleve a la solución, deben tomar decisiones y poner en marcha estrategias diferentes. El docente cumple una labor de apoyo y permite que los alumnos se pregunten, busquen soluciones, elaboren hipótesis, experimenten, recojan información, tanto de las observaciones como de diferentes fuentes, confronten opiniones, elaboren conclusiones y comuniquen los resultados obtenidos.

\section{0 - Universidad ORT Uruguay}


- Creando y recreando la temática a trabajar, contextualizándola de tal manera que sea significativa para que los alumnos sientan que les pertenece. Surge la curiosidad cuando el tema a estudiar se relaciona con las experiencias de la vida cotidiana y aquello que les preocupa: su cuerpo.

- Permitiendo que los alumnos realicen pequeñas investigaciones, desarrollando un verdadero proceso de búsqueda.

- Ayudando a comprender el pensamiento actual de la Ciencia sobre los hechos y fenómenos naturales, un modo de trabajar, un modo de preguntar a la naturaleza, de enfrentarse a los problemas y resolverlos curioseando.

- Apelando a contar situaciones vividas por personas, relatando sus historias, el contar casos reales vivenciados por los propios docentes, su propia experiencia de cómo conocer.

- Rompiendo la rutina, permitiendo "jugar" libremente con las ideas con el objetivo de aflorar inquietudes.

- En un espacio como el laboratorio; lugar con una atmósfera ideal para aprender ciencia, utilizando recursos variados, en cantidad y calidad. Especialmente aquellos denominados de última generación como los programas computacionales; todo ello haciendo que los alumnos trabajen mucho más y pregunten.

\section{Una mirada diferente}

La entrevista realizada a la Bibliotecóloga de la Institución permitió, desde otra óptica, obtener datos sobre cómo son percibidos los alumnos investigados y su relación con el aprendizaje de la Biología. Hace 10 años que trabaja allí y tiene contacto directo con todos los alumnos desde Primaria hasta el Bachillerato así como también con los docentes.

Bibliotecóloga de profesión, expresa que es importante la metodología del docente con relación al uso que se dé a la biblioteca, "... si tienes que hacer un trabajo monográfico, seguro que van a la biblioteca a buscar información..."

De ello se infiere el valor de estrategias de enseñanza que potencien el aprendizaje por investigación para estimular la curiosidad. Se destaca la importancia de la búsqueda de información, de su organización, emisión de posibles explicaciones y resolver situaciones problemáticas a partir de las interrogantes de los propios alumnos. Importante es entonces; que los docentes elaboren actividades que den alternativas a las de tipo mecánico-repetitivo, descontextualizadas y rutinarias tomando en cuenta sus intereses, sus conocimientos e ideas previas.

También se resalta el tema de ambientes saludables que faciliten la autonomía, autoestima y autogestión; “... hay una parte afectiva que es importante,...de ambiente y una persona que los estimule a una búsqueda... Yo creo que esto viene del docente..."

Cuando expresa: “...puedo ver lo que les interesa por la elección que hacen a través de la literatura que leen...cosas de adolescentes, donde ellos se identifican..." da cuenta de otro aspecto relevante que permite surgir la curiosidad: Ios contenidos a trabajar. Estos deben ser recreados haciendo hincapié en aquellos que son más relevantes para su vida: “...no sé si los temas que los alumnos de primero a tercero estudian a ellos les interesa..." 
A modo de síntesis, se reconoce la influencia de diferentes factores en el hecho de que surja la curiosidad, pero especialmente se destaca:

a- Una organización del currículum diferente en primaria que en secundaria dándose en la primera un enfoque más globalizador e interdisciplinar, acercando al escolar mucho más al medio que lo rodea. $Y$, además, una distribución temporal que permite otro tipo de comunicaciones en el aula, esencial para atender "...la necesidad de saber que tienen en primaria, es increíble..."

b- La incidencia del docente (“...para mi el disparador es el docente, porque ellos están preocupados por otras cosas..." ) en los aprendizajes que deben realizar los alumnos.

c- Una curiosidad que se manifiesta de formas distintas en relación con el nivel de conocimiento que posea como dice esta profesional: “...yo les veo investigar en primaria y se matan, y los veo en bachillerato para determinados docentes y también se matan...", "...en bachillerato, ahí, se despierta nuevamente el interés que estaba en primaria..." “...yo estoy esperándolos en bachillerato a estas generaciones..."

Los alumnos cuando llegan a bachillerato se hallan entre los 16 a 18 años, ya los cambios físicos no son tan sorprendentes, se encuentran en la búsqueda de la estructuración personal y de su ubicación en su entorno social. Presentan mayor consolidación a nivel de la personalidad, actúan con mayor responsabilidad, casi incorporados al mundo de los adultos. Han realizado una opción más o menos clara de la orientación que desean seguir, generalmente están más capacitados para controlar el proceso de aprendizaje, ampliar capacidades metacognitivas, razonamiento abstracto, mayor grado de atención. Hay un aprendendizaje por los propios medios con ideas que desarrollan ellos mismos con conceptos personales y usando de forma reglada las fuentes de informaciones disponibles, por lo que la motivación intrínseca se convierte en el principal motor del aprendizaje y la curiosidad.

También de las expresiones de los alumnos se desprende esta idea de diferentes niveles de curiosidad o que la misma es distinta según las etapas de educación formal que estén cursando: “...pregunto porque cuando yo sea grande me gustaría saber bastante de lo que me gusta y me interesa y no saber algo que no me interesa...." "...En comparación con el año pasado este año hago muchas menos preguntas, porque simplemente fui adquiriendo más conocimientos y las preguntas se me fueron acabando, pero a la vez surgían más preguntas..." Da la sensación que la curiosidad se va despertando más que nada cuanto más informados están, debido a que con cada información nueva, van surgiendo otros conocimientos para averiguar.

A medida que el alumno se va descubriendo como persona situada en una clase, descubre sus intereses o inquietudes y manifiesta su curiosidad de distintas formas. También los docentes creen que "...la curiosidad un poco surge cuando uno tiene orientación..." 


\section{A modo de conclusiones}

\section{La curiosidad dormida}

¿Qué hay detrás de una pregunta bien formulada? Todo; una forma de ver y entender el mundo, una serie de conexiones mentales, una estructura cognitiva tambaleante -hablando metafóricamente- inquisidora, cuestionadora, crítica, audaz. ¿Qué pasa en el mundo de los adultos cuando el alumno pregunta? ¿Están las familias, la sociedad, y las instituciones educativas preparadas para ello? Y los docentes, ¿quieren, están dispuestos, preparados para afrontarlas? ¿No existe una contradicción de sentimientos? Desean en teoría que los educandos logren la autonomía, la autogestión, el autogobierno como dice Ph. Jackson (2002); pero en la práctica, ¿no se les tiene miedo?, ¿no los desestabiliza?, ¿no los hace perder seguridades?

Todo docente sabe hacia dónde se dirige la clase: para ello elabora y se propone metas claras. Pero, ¿los alumnos las sienten como propias? ¿se proponen llegar a las mismas metas?

No todos los alumnos son iguales, investigaciones (Adar, 1969) sobre modelos motivacionales de los estudiantes indican que las características individuales deben ser tenidas en cuenta en el momento de planificar estrategias de enseñanza. Este autor habla de cuatro categorías de alumnos: los curiosos, los concienzudos, los sociables y los que buscan el éxito; ellos poseen determinadas preferencias por distintas formas de aprendizaje basadas en su propio "modelo motivacional".

Expresa que a los alumnos curiosos les gusta descubrir, buscar información, tomar decisiones; que prefieren situaciones donde se les den la oportunidad de seguir su propia iniciativa, actividades abiertas que les permitan expresar y satisfacer su propia curiosidad, manejando información, juzgando y decidiendo.

Estos son los alumnos del Ciclo Básico Único que se han buscado y encontrado en la investigación. No se visualizan fácilmente pero allí están, como dice la bibliotecóloga: “...en el liceo como que están muy latentes...", ocultos por diferentes máscaras, mimetizados quizás como mecanismo de defensa.

En el caso de un niño la familia se alegra cuando aparecen las preguntas porque ellas son señales de que se está creciendo intelectualmente y desarrollando la capacidad de aprender. Pero ¿qué pasa en la adolescencia?: los cuestionamientos son como astillas en la piel: son algo molestos. También en la sociedad se perciben así; ¿no movilizan las bases fundantes de las instituciones educativas: trasmitir un conocimiento socialmente aceptado? ¿Válido para quién, para quiénes? ¿Y a los docentes? ¿No les pasará algo semejante? Son algunas de las interrogantes que surgen luego de las lecturas realizadas y del análisis de los datos obtenidos.

Representamos a la curiosidad de los adolescentes estudiados como el embrión de la semilla en estado de latencia. Y, así como el agua y la temperatura adecuada son los estímulos para que ese embrión comience a crecer y a desarrollarse, los docentes con sus estrategias de enseñanza son uno de los estímulos necesarios para despertar esa curiosidad latente.

¿Despertarla cómo?: a través de la combinación de los diferentes factores que vimos o nos contaron o nos escribieron los propios actores.

Trabajando juntos docentes y alumnos; dándose y dándoles tiempo; en ambientes estimulantes, gratificantes, cálidos, de apoyo, de respeto y responsabilidades. 
Confundiéndose en ese mágico espacio del laboratorio, problematizando la temática y recreándola a partir de los intereses de los alumnos.

Recurriendo a diversos materiales -los tradicionales y los que hoy la sociedad nos ofrece como nuevas tecnologías-, para tocar, ver, oír, olfatear, degustar; en fin, sintiendo con todo el cuerpo, vivenciando los conocimientos biológicos.

Pero todo lo experencial y experimental no alcanza; hay que estar predispuesto a indagar, investigar, dudar, imaginar, descubrir, analizar, opinar, verificar. Todas ellas palabras que entre otras indican procesos y productos de personas que piensan y que los propios alumnos están dispuestos a llevar adelante y solicitan que los docentes desarrollen estrategias "...que nos hagan pensar y reflexionar..."

Solo con estrategias de enseñanza que tomen en cuenta lo antes explicitado, flexibles, con el objetivo como dice Dewey de "despertar el deseo de aprender"; y de que los alumnos sientan placer y disfruten el aprendizaje en las clases de Ciencias Biológicas, se avanzará en el proceso de despertar la curiosidad que se encuentra dormida en los alumnos.

\section{Cultivando la curiosidad \\ Lo recurrente}

Muchas pueden ser las concepciones de enseñanza de acuerdo a las diferentes corrientes epistemológicas, psicológicas y didácticas a que adhiera el docente. Ello supone tomar decisiones con cierto grado de intencionalidad sobre qué conocimientos (conceptuales, procedimentales, actitudinales), en qué momento y de qué forma deben ser aprendidos.

El tratamiento a nivel curricular de las conductas estratégicas que debe desarrollar el alumno debe estar relacionado con el tipo de actividades que el profesor establezca en la clase. Las actividades, los recursos... y la comunicación que se instalen en la interacción con ellos, permitirán captar el sentido y el significado del uso estratégico de los procedimientos y los apliquen de forma autónoma y eficaz.

De lo investigado se desprende que los objetivos perseguidos por los profesores son enseñar a sus alumnos el conocimiento y la utilización adecuada de estrategias de aprendizaje necesarias para resolver una tarea o adquirir un conocimiento. También reflexionar sobre las que utilizan para realizar una determinada tarea, pero no acerca del desarrollo de estrategias interrogativas.

Una enseñanza para la formulación de preguntas debe proporcionar muchas oportunidades para que los alumnos las formulen en sus interacciones en el aula. Enseñar a los alumnos a que utilicen la estrategia de hacer preguntas y trabajarlo como contenido procedimental, es uno de los aspectos que los propios alumnos consideran conveniente y necesario como se desprende de sus palabras "...Siento que tengo que preguntar porque si no me siento una persona sin conocimientos, ..."

Son conscientes de la importancia de preguntar en clase con el fin de conocer y aprender, además de que poseen habilidades metacognitivas. Se infiere que son alumnos auto-regulados ya que asumen la responsabilidad del progreso de su propio aprendizaje a través de las preguntas que formulan.

Expresan: “...Me gustaría que sean las clases más activas, que el profesor pregunte y nos haga cuestionarnos las cosas...". Están pidiendo que los docentes piensen en estrategias que permitan a los alumnos realizar preguntas que los alienten a reconocer que dicho proceso tiene una utilidad que va más allá de la clase. 
Enseñar a los alumnos a que se formulen preguntas, qué reconozcan que tipo de cuestionamientos les permiten llegar a la comprensión de un contenido, también es valorado por los docentes "...el alumno que realiza una pregunta que permite ver la asociación que hizo, agrupar una idea que tenía ahí que lo iluminó para seguir en una búsqueda...". Plantean que tanto los resultados obtenidos, como la calidad del aprendizaje, cuando se hacen preguntas, son muy diferentes.

¿Qué hacer frente a este reconocimiento?: los docentes deberán reflexionar sobre los caminos que hay que seguir, las decisiones que tienen que tomar y los desafíos que deben afrontar. Las limitantes son muchas, no podrán cambiar el currículum, el contexto sociocultural, la carga horaria, etc.

Si los alumnos son curiosos y lo que sucede es que no lo manifiestan, los docentes tienen una gran responsabilidad: cultivar la curiosidad. Ellos presentan una predisposición oculta, tienen la capacidad y la inclinación a preguntar, a explorar, inquirir, buscar claridad, profundizar nuevas dimensiones, a pensar crítica y reflexivamente. El intentar desarrollarlas llevará tiempo y no alcanzará con que se dediquen algunas clases, deberá atenderse reiteradamente a lo largo de todo el curso, de todo el programa de manera planificada. Solo así se manifestará la curiosidad esperando que con el tiempo se revele e imponga en la clase automáticamente.

Muchos factores inciden para que un alumno pregunte. Con el propósito de que adquiera la estrategia de preguntar se deberá trabajar en la clase desde muchos lugares. Lo recurrente en los resultados de la investigación es la necesidad de variar las actividades y los recursos, rediseñar los espacios y el tiempo, recrear los contenidos y especialmente la necesidad de un docente que escuche mucho más.

Pero, el hecho es ir más allá de enseñar al alumno a preguntar -los relatos de los alumnos dicen que saben del valor de la pregunta para comprender y los docentes reconocen de su importancia en el aprendizaje-; hace falta más que capacidades personales para comprender. Se debe estar abierto a la exploración, a correr riesgos, buscar nuevos caminos, crear desafíos y esto no se puede enseñar en pocas clases, se deben desarrollar en el contexto de una cultura: la cultura del aula, de la cual cada docente es responsable.

Desarrollar una cultura de aula pensada en despertar la curiosidad de los alumnos a través de una postura tal que permita que ellos sean realmente protagonistas, deberá ser aquella en la que:

- se crean oportunidades y destina tiempo para que pregunten, creando el clima de aula adecuado para ello.

- se los alienta a que estén alerta a sus propias predisposiciones a preguntar y a las de sus compañeros, se los impulsa a cuestionar y a que construyan mejores preguntas y busquen las oportunidades para formularlas.

- se los ayuda a través del análisis de lo pertinente de sus preguntas para avanzar en el conocimiento.

- el propio docente actúa como "modelo" en el discurso del aula, donde todas las clases, en todos los temas muestra como logró ciertos conocimiento, qué preguntas se realizó, cuándo, en qué momento y lo valiosas que son para seguir aprendiendo.

Quizás el camino sea como el modelo que fue la madre de Isidor Rabi Premio Nobel de Física para él, idea que se desprende de sus palabras con las que dimos comienzo e inspiraron esta investigación e instalaron desde ese ámbito familiar, la cultura de la pregunta.

Esta estrategia que comienza siendo consciente, intencional, planificada, poco a poco se introduce en la cotidianeidad de la clase para dar comienzo a una genuina enseñanza en la 
que los alumnos son realmente activos, capaces de resolver problemas con eficacia a partir de sus intereses, tomar decisiones razonadas y disfrutar. "Vivir" al estudiar Biología, donde en diferentes momentos docentes y alumnos rotan para ocupar el lugar del "poder" y en otros, se comparte la toma de decisiones.

\section{Lo particular}

En las entrevistas los docentes explicitan vivencias e inquietudes sobre diferentes tópicos: los cambios sociales, la vida en familia entre otras, y realizan una comparación entre lo que viven los chicos hoy diferenciándolas con épocas pasadas. En un pasaje de ellas se expresa “...yo cuando crecí en la época del liceo la familia era mucho más que reunirnos. No era la familia se va a reunir el domingo a las 12 porque al abuelo le gusta comer, no, era mucho más que eso..." Además, hablando sobre las clases: “...Bueno, ahora quedaron que les tengo que narrar una experiencia en vía pública..."

Frente a estas ideas surgen interrogantes:

¿Por qué no animarse a pensar sobre la necesidad de que los docentes tornaran las clases en lugares más "cálidos", más humanos?

¿Por qué no recordar que todo el conocimiento que se tiene ha sido obtenido en el contexto de la vida de alguien, resultado de sus esperanzas, temores y sueños?

¿No encuentran los docentes en la narrativa una estrategia de enseñanza poderosa para que afloren las preguntas de los alumnos?

Los estudios acerca de la narración en la enseñanza, su sentido y su naturaleza, han sido abordados por J. Bruner. En el siglo XX se viene produciendo un corrimiento hacia la lingüística, del impacto de la matemática y la lógica con respecto a la construcción del conocimiento. El propio Jackson habla no solo de la fuerza de la narrativa en las prácticas de enseñanza sino en el saber pedagógico.

El retorno a la narrativa indica que hoy se reconsidere el valor de la forma y la función de los relatos en todos los aspectos de la vida humana, especialmente, en la educación donde aún hoy se impone un sesgo conductista. Desde el punto de vista epistemológico las historias enseñan algo, son las que hacen que se sea parte de una cultura.

Por medio de los relatos no solo se trasmite un saber; ellos son en sí mismo el saber que se desea que los estudiantes posean. A través de la narrativa se puede "encantar" a los alumnos, captar su atención; gracias a su fuerza imaginativa los llevan a entender mejor.

Los relatos poseen una naturaleza transformadora, permiten comprender el mundo de diversas maneras y ayudan a expresar nuevas ideas a los demás. Pueden además modificar en términos morales a los alumnos. A través de las narraciones los docentes de ciencias quizás puedan despertar el interés de los alumnos, ayudar a resolver lo inesperado, a comprender y a aclarar las dudas.

Recordemos que los relatos están sometidos a la interpretación pero no a la explicación. Se puede explicar la estructura del ADN, pero solo se puede interpretar a través de la narración los puntos de vista de los investigadores que llevaron a imaginar dicha estructura. De esta forma se ayuda a los alumnos a adquirir un conocimiento de orden superior (Perkins, 2001); según la forma utilizada en la resolución de problemas, búsqueda de evidencias, investigación mediante la formulación de preguntas valiosas y la construcción de teorías capaces de responderlas.

\section{6 - Universidad ORT Uruguay}


Sin caer en que las clases se conviertan en historia de las ciencias, se hace necesario recordar que el proceso de creación de la ciencia es narrativo, buscando un equilibrio entre la enseñanza de los resultados de la ciencia y la viva creación de la ciencia.

Contar o leer historias sobre distintos hombres de ciencia podría establecer un rico diálogo en el cual aparecerían muchas interrogantes; pero lo importante es que los alumnos puedan "pasar del asombro a la curiosidad "activa", y saber transformar las preguntas en función del proceso, de los marcos de referencia y del nivel semántico de los alumnos". (Giordan, 1995,197)

Para ello la acción del docente consiste en hacer evolucionar las preguntas que se plantean los alumnos (decodificar los conceptos a tratar) hasta llegar a la formulación de un verdadero problema científico. A.Giordan y G. de Vecchi $(1995,192)$ dicen "en todos los estudios que hemos realizado en historia de las ciencias sobre construcción de los conceptos, hemos comprobado que el saber se ha construido siempre a partir de una pregunta, o de varias preguntas planteadas de forma sucesiva. (...), cuando no hay verdadera curiosidad, se asiste a una parada en la construcción del pensamiento". ¿No podrían ser los relatos de los docentes un potente instrumento para lograrlo?

Con relación a las preguntas, Bruner $(1997,145)$ dice: "el arte de plantear preguntas provocadoras puede ser tan importante como el arte de dar respuestas claras". Esto hace pensar que no solo la curiosidad se pone en evidencia a través de cuestionamientos sino en la formulación de buenas respuestas "vivas", fundamentaciones, organización de las ideas y su transmisión. ¿No hay acá narrativa?

Al finalizar se recuerda las palabras de Ph. Jackson, "Soy un maestro sólo en la mente de alguien que cree que yo podría enseñarle algo que no sabe. Pero como yo no poseo el conocimiento que esa persona anhela, enseñar consiste en seguir generando el deseo del conocimiento". (McEwan y Egan 1998).

Los docentes transitan los difíciles límites de hacer recorridos oscuros; deben desprenderse algunas veces de su rol y volverse seres más humanos. Aspirar a convertirse en docentes memorables; aquellos que se han separado del modelo de la transmisión de información y provocan en sus alumnos la capacidad de formular preguntas, mediante estrategias de enseñanza que permitan aflorar la curiosidad dormida. Curiosidad que permite aumentar la capacidad de aprender, como parte del proceso generativo de la vida. 


\section{Bibliografía}

ASIMOV, I. 1993. Nueva guía de las Ciencias. Buenos Aires: Plaza \& Janés Editores.

AUSUBEL, D. 1978. Psicología Educativa. Un punto de vista cognoscitivo. México: Trillas. ASTOLFI, J. P. 1999. El “error”, un medio para enseñar. Sevilla: Díada.

BURBULES, N. 1999. El diálogo en la enseñanza. Buenos Aires: Amorrortu editores. BRUBACHER, J., et al. 1994. Cómo ser un docente reflexivo. Barcelona: Gedisa.

CAMILLONI, A., et al. 2001. Corrientes didácticas contemporáneas. Buenos Aires: Paidós. CARBONELL, J. 2001. La aventura de innovar. Madrid: Morata.

CARRETERO, M. 1997. Construir y enseñar las ciencias experimentales. Buenos Aires: Aique.

CASTORINA, J., et al. 1999. Piaget-Vigostky contribuciones para replantear el debate. Buenos Aires: Paidós.

CAZDEN, C. 1991. El discurso en el aula. Barcelona: Paidós.

CLAXTON, G. 1994. Educar mentes curiosas. Madrid: Visor.

COLL, C. 1996. Aprendizaje escolar y construcción del conocimiento. Buenos Aires: Paidós. COLL, C. 1997. ¿Qué es el constructivismo? Buenos Aires: Magisterio del Río de la Plata. COOK, T., et al. 1986. Métodos cualitativos y cuantitativos en investigación. Madrid: Morata. CHALMERS, A. 1987. ¿Qué es esa cosa llamada ciencia? 6ª.ed. Buenos Aires: Siglo XXI. DELVAL, J. 2000. Aprender en la vida y en la escuela. Madrid: Morata.

DE LA TORRE, S. 2000. Estrategias didácticas innovadoras. Barcelona: Octaedro.

DÍAZ BARRIGA, A. 1994. Docente y programa. 2ª .ed. Buenos Aires: Aique.

DÍAZ BARRIGA, A. 1997. Didáctica y currículum. México: Paidós.

EISNER, E. 1994. Cognición y currículum. Buenos Aires: Agenda Educativa.

EGGEN-KAUCHAK. 2000. Estrategias docentes. Buenos Aires:Fondo de cultura económica. FABRA, M. L. 2001. Hablar y escuchar. Barcelona: Paidós.

FELDMAN, D. 1999. Ayudar a enseñar. Buenos Aires: Aique.

FREINET, C. 1996. La escuela moderna francesa. Madrid.: Morata.

GIORDAN, A. 1995. Los orígenes del saber. $2^{a}$.ed. Sevilla.: Díada.

GRUNDY, S. 1987. Producto o praxis del currículum. Madrid: Morata.

GUMILA, O. 1995. Aula mágica. Montevideo: Fin de siglo.

HARLEN, W. 1989. Enseñanza y aprendizaje de las ciencias. $2^{\mathrm{a}}$. Ed. Madrid: Morata.

HERNÁNDEZ, R., et al.1998. Metodología de la investigación. 2ª.ed. México: Mc Graw Hill. HUBERMAN, S. 1996. Cómo aprenden los que enseñan. Buenos Aires: Aique.

JACKSON, P. 1999. Enseñanzas implícitas. Buenos Aires: Agenda educativa.

JACKSON, P. 1998. La vida en las aulas. Madrid: Morata.

JACKSON, P. 2002. Práctica de la enseñanza. Buenos Aires: Amorrotu editores.

68 - Universidad ORT Uruguay 
KAPLAN, C. s.f. 1989. Buenos y malos alumnos. Buenos Aires: Aique.

KEMMIS, D. 1988. El currículo: más allá de la teoría de la reproducción. Madrid: Morata. LEMKE, J. 1997. Aprender a hablar ciencia. Barcelona: Paidós.

LITWIN, E. 2000. Las configuraciones didácticas. Buenos Aires: Paidós.

McCOMBS, B. 2000. La clase y la escuela centradas en el aprendiz. Barcelona: Paidós.

MERCER, N. 1997. La construcción guiada del conocimiento. Barcelona: Paidós.

MEIRIEU, P. 1992. Aprender, sí pero ¿cómo? Madrid: Octaedro.

MINNICK SANTA, C. 1994. Una didáctica de las ciencias. 2ª ${ }^{\mathrm{a}}$ ed. Buenos Aires: Aique.

MONEREO, C. 2001. Estrategias de enseñanza y de aprendizaje. 9a.ed. Barcelona: Graó.

MORIN, E. 1998. Introducción al Pensamiento complejo. Barcelona: Gedisa.

NOVAK, J. 1982. Teoría y práctica de la educación. Madrid: Alianza Universitaria.

OBIOLS, G. 2000. Adolescencia, postmodernidad y escuela secundaria. Buenos Aires: Kapeluz.

PERRENOUD, P. 2000. Construir competencias desde la escuela. Santiago de Chile: Dolmen Ediciones.

PERKINS, D. 2001. La escuela inteligente. Barcelona: Gedisa.

POZO, I. 2001. Aprendices y maestros. Madrid: Alianza editorial.

SANTOS GUERRA, M. A. 2000. La escuela que aprende. Madrid: Morata.

SCHÖN, D. 1992. La formación de profesionales reflexivos. Barcelona: Paidós.

STENHOUSE, L. 1998. Investigación y desarrollo del currículum. Madrid: Morata.

TAYLOR, S. y BOGDAN, R. 1987. Introducción a los métodos cualitativos de investigación. Buenos Aires: Paidós.

VELILLA BARQUERO, R. 1974. Saussure y Chomsky introducción a la lingüística. $6^{a}$.ed. Bogotá: Editorial Cincel.

VIGOTSKY, L. 1987. Historia del desarrollo de las funciones psicológicas superiores. La Habana: Ed. Científico-Técnica.

VIGOTSKY, L. 1988. El desarrollo de los procesos psicológicos superiores. México: Grijalbo.

WITTROCK, M. 1986. La investigación en la enseñanza: enfoques, teorías y métodos I y II. Barcelona: Paidós.

WOOLFOLK, A. 1996. Psicología educativa. 6ª.ed. Naucalpan de Juárez: Pretince-Hall.

*El Artículo se enmarca en la tesis de maestría de la autora, dirigida por la Mag. Mabel Ruíz. Año 2004.

**Master en Educación, Universidad ORT Uruguay. Diploma en Educación, Universidad ORT Uruguay. Profesora de Educación Media, INADO. Docente, Instituto de Profesores Artigas,. Docente de enseñanza media a nivel público y privado. 